\title{
Apolipoprotein E genotypes in Mexican patients with Parkinson's disease
}

\author{
M.P. Gallegos-Arreola ${ }^{a}, *$, L.E. Figuera ${ }^{b}$, G.G. Ortiz ${ }^{c}$, F.J. Jiménez-Gil ${ }^{d}$, J. Ramírez-Vega ${ }^{\mathrm{e}}$, \\ J.L. Ruíz-Sandoval ${ }^{f}$, A.M. Puebla-Pérez ${ }^{g}$, R. Troyo-Sanroman ${ }^{\text {, }}$ J.E. García-Ortiz ${ }^{\mathrm{b}}$, \\ J. Sanchez-Corona ${ }^{\mathrm{a}}$ and G.M. Zúñiga-González ${ }^{\mathrm{a}}$ \\ ${ }^{a}$ Medicina Molecular, Instituto Mexicano del Seguro Social, Guadalajara, Jalisco, México \\ ${ }^{\mathrm{b}}$ Genética, Instituto Mexicano del Seguro Social, Guadalajara, Jalisco, México \\ ${ }^{\mathrm{c}}$ Neurociencias, Instituto Mexicano del Seguro Social, Guadalajara, Jalisco, México \\ ${ }^{\mathrm{d}}$ Centro de Investigación Biomédica de Occidente, Servicio de Neurología, UMAE, Hospital de Especialidades, \\ Centro Médico Nacional de Occidente (CMNO), Instituto Mexicano del Seguro Social, Guadalajara, Jalisco, \\ México

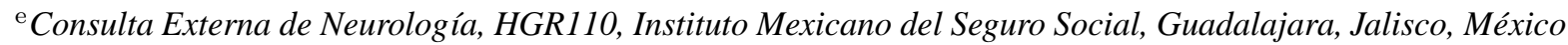 \\ ${ }^{\mathrm{f}}$ Hospital Fray Antonio Alcalde, Guadalajara, Jalisco, México \\ ${ }^{\mathrm{g}}$ Laboratorio de Inmunofarmacolog ía, Centro Universitario de Ciencias Exactas e Ingenierias, Guadalajara, \\ Jalisco, México \\ ${ }^{\mathrm{h}}$ Departamento de Fisiología, Centro Universitario de Ciencias de la Salud, Universidad de Guadalajara, \\ Guadalajara, Jalisco, México
}

\begin{abstract}
Background: The association of the apolipoprotein (Apo E) -epsilon4 allele to neurodegenerative diseases such as Parkinson's disease (PD) has been analyzed in several studies. This association has been identified by amyloid deposits and neurofibrillary tangles in the brains of patients with neurodegenerative diseases.

Method: In this study the possible relationship between Apo E alleles and PD patients was analyzed in 105 patients with PD and 107 healthy controls from a Mexican population.

Results: Allele analysis in PD vs. controls was: $\varepsilon 2$ in $6 \%$ and $2.3 \%$, respectively; $\varepsilon 3$ in $73 \%$ and $88.3 \%$; and $\varepsilon 4$ in $21 \%$ and $9.4 \%$. The $\varepsilon 3$ allele showed a protective risk effect with an Odds ratio (OR) of 0.36 (95\%CI $0.20-0.61)$ and $p<0.05$; contrary results were observed for the $\varepsilon 4$ allele, which showed an increased risk for PD, with an OR of 2.57(95\% CI 1.42-4.79) and $p<$ 0.05 . Upon multivariate analysis showed PD risk was evident in patients who were carriers of the genotype $\varepsilon 3 / \varepsilon 4$; age group (fifty or more years) and had exposure to pesticides and solvents $(p<0.05)$.

Conclusions: The $\varepsilon 3 / \varepsilon 3 ; \varepsilon 3 / \varepsilon 4$ genotypes of the Apo E, were positively associated with sporadic PD.
\end{abstract}

\section{Introduction}

Parkinson's disease (PD), the second most common neurodegenerative disease, is more frequent in males and is present in about $2 \%$ of the adult population

* Corresponding author: Martha Patricia Gallegos Arreola, Sierra Mojada No. 800, Col. Independecia, Guadalajara, Jalisco, C.P. 44340, México. E-mail: marthapatriciagallegos08@gmail.com; marthaga@mail.udg.mx. over 65 years of age, although it has been observed in younger people [1-3]. It is a multifactorial disease but more than $10 \%$ of cases are hereditary and the prevalence varies with respect to the population analyzed, gender and age [2-4]. Parkinson's disease is diagnosed using clinical criteria, based on the presence of: tremor, bradykinesia, akinesia, and rigidity [2-4]. Basal ganglia dysfunction leads to the majority of motor disorders that are varied and affect patients' motor control, such as: reflexes (rigidity), autonomous movements (hypokinesia and tremor) and voluntary move- 
ments (bradykinesia) [2,4]. Typically, the PD patient's posture is in flexion of both the head and trunk; of the joints, the arms and legs. It's common to find a degree of intellectual dysfunction that includes mild cognitive impairment in perception, memory and the expression of language in about $10 \%$ of patients there is frank dementia. Generally, postural abnormalities occur later in the course of PD [3]; with progressive neuronal loss being more evident in the compact area substantia nigra, and are associated with the presence of Lewy bodies (ubiquitinated protein deposits) in the cytoplasm of neurons [3].

The cause of the PD is unknown and several studies have shown that in addition to the genetic component there are environmental risk factors for PD development that include: drinking well water, contact with herbicides and pesticides, and continuous exposure to industrial pollutants [2-5]. Different locus genes have been associated to PD [6], among which is the apolipoprotein E gene on chromosome 19q13.2, that has been identified by its important function on the transporting of lipids in plasma and neurons [3]. Found in many organs, the Apo E is synthesized in the brain by astrocytes and can be internalized by nerve cells [3]. It is a polymorphic protein made up of 299 amino acids and three known isoforms (E2, E3 and E4) in the plasma [7]. These isoforms are under the control of 3 dominant, independent alleles: $\varepsilon 3, \varepsilon 2$, and $\varepsilon 4$ [7]. The alleles $\varepsilon 2$ and $\varepsilon 3$ have been known to confer a protective effect against Alzheimer's and PD diseases, and have been associated with longevity $[3,8]$; while to the contrary, it has been observed that the $\varepsilon 4$ allele is associated to Alzheimer's and PD. The Apo E gene has been postulated as a candidate for its association to neurodegenerative diseases such as Alzheimer's disease and PD [3,8]. Frequency of the Apo E allele varies depending on the population studied: the $\varepsilon 3$ allele, frequently accompanying the $\varepsilon 2$ allele, has most commonly been the one to reduce low-density lipoprotein (LDL) cholesterol levels, while higher total- and LDLcholesterol levels typically occur with the $\varepsilon 4$ allele; which, forming monofibrillary peptides, precipitates and forms dense structures (amyloid plaques) that are the main component of neurofibrillary tangles [8]. Also, it has been shown that the E3 and E2 isoforms have affinity to the Tau protein [9]; which, confers protection from hyperphosphorylation on the Tau protein [8-10]. However, the exact mechanism by which this happens, whether through the cytoskeleton and Tau protein or by alteration in the cholesterol transport, is unknown. Finally, the peripheral role of the Apo $E$ alters the risk of heart disease, which is related to neurodegenerative diseases $[9,10]$.

Neurodegenerative diseases, particularly those with symptoms of involuntary movements and dementia, are a growing public health problem in our country. PD is one of the most common and in a population over 60 years of age in Tepatitlan, Jalisco, Mexico, its prevalence has been described as 2.7/1000 [11]; calculated to affect 1-2 for every 1,000 people in the general population worldwide, and 1-3\% in elderly over 60 years of age. Nonetheless, part of the problem lies in the fact that currently there is no known precise data about the incidence and prevalence of this disease in our country. According to the above, if more than 556,526 people between the ages of 50 and 60 years of age live in Jalisco [12], there could be approximately 16, 695.78 afflicted with PD. The aim of the present work was to evaluate the relationship between polymorphisms of the Apo $E$ gene and PD, in a sample from the State of Jalisco.

\section{Material and methods}

We recruited 105 patients with PD and 107 healthy subjects from Mexicans living in and around the city of Guadalajara. Patients were recruited between January 2003 and January 2008 from: Departamento de Neurología, Hospital Civil "OPD Fray Antonio Alcalde”, Universidad de Guadalajara, Hospital de Especialidades, CMNO, and the Clínica 110, IMSS, Guadalajara; Jalisco, México. PD cases were confirmed by medical, neurological examination, and a neurologist performed diagnostic investigations on all those who screened positive. PD was diagnosed in subjects with at least two of the four cardinal signs - resting tremor, bradykinesis, rigidity, and postural disturbances - and no other apparent cause of Parkinsonism. Controls without PD were recruited from healthy volunteers, and their habits and family histories were investigated.

Personal data collection entailed interviewing both groups with the use of a short questionnaire that included items on: age, sex, detailed information on recent and past use of tobacco, caffeine and alcohol consumption, and exposure to pesticides. All individuals signed a letter of informed consent.

Blood samples for DNA extraction and genotyping according to standard protocols were available for 105 patients with PD and 107 healthy controls [13].

The presence of the Apo E alleles ( $\varepsilon 2, \varepsilon 3$ and $\varepsilon 4$ ) was determined by DNA amplification in a total PCR 
Table 1

General characteristics of the study groups

\begin{tabular}{|c|c|c|c|c|c|c|c|c|}
\hline \multirow[t]{2}{*}{ Variables } & \multicolumn{3}{|c|}{ Parkinson's disease } & \multicolumn{2}{|c|}{ Controls } & \multirow{2}{*}{$\frac{\text { Controls vs. PD patients }}{p \text { value }}$} & \multirow[t]{2}{*}{ OR } & \multirow[t]{2}{*}{$(95 \% \mathrm{CI})$} \\
\hline & & $(n=105)$ & $\%$ & $(n=107)$ & $\%$ & & & \\
\hline Years $($ mean $\pm \mathrm{SD})$ & & $63 \pm 9$ & & $50 \pm 14$ & & $0.001^{* *}$ & & \\
\hline Age group & $<50$ & $(9)$ & 9 & $(56)$ & 52 & $0.000^{*}$ & 11.71 & $(5.36-25.59)$ \\
\hline$(\text { years })^{* * *}$ & $\geqslant 50$ & (96) & 91 & (51) & 51 & & & \\
\hline \multirow{2}{*}{ Gender } & Female & (42) & 40 & $(60)$ & 56 & & & \\
\hline & Male & (63) & 60 & (47) & 44 & $0.02^{*}$ & 1.92 & $(1.11-3.31)$ \\
\hline \multirow{2}{*}{ Smoking status } & Yes & (42) & 40 & (63) & 59 & $0.006^{*}$ & 0.47 & $(0.27-0.81)$ \\
\hline & No & (63) & 60 & (44) & 41 & & & \\
\hline \multirow{2}{*}{ Caffeine } & Yes & (45) & 43 & (74) & 69 & $0.000^{*}$ & 0.33 & $(0.19-0.59)$ \\
\hline & No & (60) & 57 & (33) & 31 & & & \\
\hline \multirow{2}{*}{ Alcohol } & Yes & (40) & 38 & (35) & 33 & 0.41 & 1.27 & $(0.72-2.23)$ \\
\hline & No & $(65)$ & 62 & (72) & 67 & & & \\
\hline \multirow{2}{*}{$\begin{array}{l}\text { Pesticides, herbicides } \\
\text { and solvents }\end{array}$} & Yes & (58) & 55 & (14) & 13 & $0.000^{*}$ & 8.20 & $(4.15-16.20)$ \\
\hline & No & (47) & 45 & (93) & 87 & & & \\
\hline \multirow{2}{*}{ Well water } & Yes & (40) & 38 & (24) & 22 & $0.013^{*}$ & 2.13 & (1.17-3.88) \\
\hline & No & (65) & 62 & (83) & 78 & & & \\
\hline
\end{tabular}

$n$ : sample; SD: standard deviation; ${ }^{*}$ significant different by chi-Square test, and ${ }^{* *} \mathrm{t}^{\prime}$ test, ${ }^{* * *}$ (groups stratified in $\geqslant 50$ years old; based on the average age of onset of Parkinson symptoms as manifested in the literature)

volume of $25 \mu$ l containing $200 \mathrm{mM}$ dNTPs, 34 pmol of primers, $3.0 \mathrm{mM} \mathrm{MgCl}_{2}$, and $1.5 \mathrm{U}$ Taq polymerase (Invitrogen, Life Technologies), and DMSO 10\%, using the following primers: F4 5'-ACAGAATTCGCCCCG GCCTGGTACAC-'3' and F6 5' -TAA GCT TGG CAC GGC TGT CCA AGG A-3' (14). These primers amplify a fragment $174 \mathrm{bp}$ on the Apo E gene. The PCR conditions consisted of an initial melting temperature of $94^{\circ} \mathrm{C}$ ( $\left.5 \mathrm{~min}\right)$ followed by 34 cycles of melting $\left(94^{\circ} \mathrm{C}\right.$, $15 \mathrm{~s})$ annealing $\left(55^{\circ} \mathrm{C}, 28 \mathrm{~s}\right)$, and extension $\left(72^{\circ} \mathrm{C}, 45 \mathrm{~s}\right)$ and final extension $72^{\circ} \mathrm{C}(7 \mathrm{~min})$. To distinguish between the alleles, the amplified product were subjected to restriction enzyme analysis with HhaI (New England Biolabs, Beverly, MA, USA), according to the manufacturer's instructions. The samples were separated using $12 \%$ polyacrylamide gel electrophoresis (19:1) followed by silver staining [15], which revealed $91,83 \mathrm{bp}$ fragments for $\varepsilon 2$ allele, 91,48 and 35 bp for $\varepsilon 3$ allele, and $72,48,35$ and $19 \mathrm{bp}$ [16].

The frequencies of the Apo E polymorphisms in PD patients compared with controls were tested for significance using Chi-squared or Fisher's exact tests. Odds ratios (OR) and $95 \%$ confidence intervals (CI) were also calculated. Logistic regression of $p<0.05$ was regarded as statistically significant.

\section{Results}

Among the PD patients, the means age was 63 years, $60 \%$ were male, $40 \%$ were tobacco smokers, $38 \%$ drank well water and consumed alcohol, $43 \%$ used caf- feine, and $55 \%$ had pesticide or herbicide exposure (Table 1).

Table 2 shows the number of cases and controls by Apo $E$ polymorphism status. The frequency of the $\varepsilon 3 \varepsilon 3$ genotype was $52 \%(55 / 105)$ in the PD group, compared to $80 \%(86 / 107)$ from control group; the OR was $0.27(95 \% \mathrm{CI} 0.14-0.52)$ and $p<0.001$. The frequency of the $\varepsilon 3 \varepsilon 4$ genotype was $38 \%$ (40/105) in the PD group and $16 \%(17 / 107)$ in the control group, which was significantly different; with an OR of 3.26(95\%CI, 1.63-6.66) and $p<0.001$. The genotype distribution frequencies from cases and controls, according to the likelihood ratios, were all consistent with the Hardy Weinberg equilibrium.

A multivariate logistic regression analysis, in which the groups were considered to be the dependent variable, was carried out with the following independent variables: Apo $E$ genotypes $(\varepsilon 3 / \varepsilon 3: \varepsilon 3 / \varepsilon 4)$, gender (male, female), age group $(<50, \geqslant 50$ years $)$, consumption of tobacco and caffeine (yes or no), and herbicidespesticides exposure (yes or no) (Table 3), no other data were recorded.

\section{Discussion}

PD is the second most common neurodegenerative disorder and is more frequently observed in males in most populations studied, suggestive of an incidence of at least a two-fold greater risk of developing PD in males. Some studies have addressed the clinical and biochemical differences between genders [17]. In the present study, this trend continued. The comparison 
Table 2

Genotype and allelic frequencies of Apo $E$ polymorphism in the study groups

\begin{tabular}{|c|c|c|c|c|c|c|}
\hline \multirow[t]{2}{*}{ Genotypes } & \multicolumn{2}{|c|}{ Parkinson's disease } & \multicolumn{2}{|c|}{ Controls } & \multicolumn{2}{|c|}{ PD patients vs. Controls } \\
\hline & $(n)$ & $\%$ & $(n)$ & $\%$ & OR (95\% IC) & $p$ value \\
\hline$\varepsilon 2 / \varepsilon 2$ & (4) & 4 & (1) & 1 & $2.55(0.4-27.20)$ & 0.44 \\
\hline$\varepsilon 3 / \varepsilon 3$ & (55) & 52 & (86) & 80 & $0.27(0.14-0.52)$ & $0.001^{*}$ \\
\hline$\varepsilon 4 / \varepsilon 4$ & (1) & 1 & (0) & 0 & $2.06(0.11-122.47)$ & 0.61 \\
\hline$\varepsilon 2 / \varepsilon 3$ & (3) & 3 & (0) & 0 & $4.19(0.40-208.03)$ & 0.21 \\
\hline$\varepsilon 2 / \varepsilon 4$ & (2) & 2 & (3) & 3 & $0.67(0.06-6.01)$ & 1.0 \\
\hline$\varepsilon 3 / \varepsilon 4$ & $(40)$ & 38 & (17) & 16 & $3.26(1.63-6.66)$ & $0.001^{*}$ \\
\hline Total & (105) & 100 & 107 & 100 & & \\
\hline Alleles & $(2 n)$ & & $(2 n)$ & & & \\
\hline$\varepsilon 2$ & (13) & 6 & (5) & 2.3 & $2.76(0.90-10.04)$ & 0.08 \\
\hline$\varepsilon 3$ & (153) & 73 & (189) & 88.3 & $0.36(0.20-0.61)$ & $0.001^{*}$ \\
\hline$\varepsilon 4$ & (44) & 21 & $(20)$ & 9.4 & $2.57(1.42-4.79)$ & $0.001^{*}$ \\
\hline Total & (210) & 100 & (214) & 1.0 & & \\
\hline
\end{tabular}

OR: Odds ratio; CI: confidence interval; ${ }^{*}$ significant $(p<0.05)$ by chi-square test.

Table 3

Multivariate Logistic regression analysis in the studied groups

\begin{tabular}{|c|c|c|c|c|c|c|c|c|}
\hline \multirow[t]{2}{*}{ Variable } & \multirow[t]{2}{*}{$\mathrm{B}$} & \multirow[t]{2}{*}{$\mathrm{SE}$} & \multirow[t]{2}{*}{ Wald } & \multirow[t]{2}{*}{$\mathrm{Df}$} & \multirow[t]{2}{*}{ Significance } & \multirow[t]{2}{*}{ OR } & \multicolumn{2}{|c|}{$95.0 \% \mathrm{CI}$} \\
\hline & & & & & & & Lower & Upper \\
\hline Age group & 2.294 & 0.465 & 24.345 & 1 & 0.000 & 9.916 & 3.986 & 24.668 \\
\hline Tobacco & -0.895 & 0.374 & 5.715 & 1 & 0.017 & 0.409 & 0.196 & 0.851 \\
\hline Caffeine & -0.893 & 0.368 & 5.890 & 1 & 0.015 & 0.409 & 0.199 & 0.842 \\
\hline Herbicides, pesticides and solvent & 1.611 & 0.409 & 15.535 & 1 & 0.000 & 5.006 & 2.248 & 11.158 \\
\hline$\varepsilon 3 / \varepsilon 3$ & -1.066 & 0.415 & 6.608 & 1 & 0.010 & 0.345 & 0.153 & 0.776 \\
\hline Age group & 2.278 & 0.462 & 24.295 & 1 & 0.000 & 9.757 & 3.944 & 24.138 \\
\hline Tobacco & -0.868 & 0.369 & 5.517 & 1 & 0.019 & 0.420 & 0.203 & 0.866 \\
\hline Caffeine & -0.903 & 0.362 & 6.221 & 1 & 0.013 & 0.405 & 0.199 & 0.824 \\
\hline Herbicides, pesticides and solvent & 1.709 & 0.400 & 18.274 & 1 & 0.000 & 5.521 & 2.522 & 12.086 \\
\hline$\varepsilon 3 / \varepsilon 4$ & 1.070 & 0.438 & 5.974 & 1 & 0.015 & 2.917 & 1.236 & 6.881 \\
\hline
\end{tabular}

of the study groups showed that men have a 1.5 times higher risk of developing PD than women $(p<0.05)$. On the other hand, it has been shown that multifactorial etiology such as: tobacco use, caffeine consumption, exposure to herbicides, pesticides and solvents, and drinking well water, contribute to the risk for PD. In these variables we observed significant differences. Similar studies have been reported by [18-20].

The common neurodegenerative diseases are predominantly idiopathic disorders of unknown pathogeneses, but several investigations have studied the existence of factors for genetic susceptibility to PD [21]. These studies have established that the inheritance of one or more $\varepsilon 4$ glleles increases an individual's risk for development of cardiovascular, atherosclerosis in Alzheimer's and PD, because the $\varepsilon 4$ allele has been associated with higher plasma levels of total cholesterol and low density cholesterol, which are considered risk factors. Conversely, the $\varepsilon 2$ allele has been associated with low lipid concentration and protection [22]. The Apo E, a major protein component of lipoprotein in the central nervous system, participates in lipid metabolism and cholesterol transport, and facilitates the binding of apolipoproteins to low-density lipoprotein receptors; thereby, sustaining the lipoprotein cholesterol available to the cell [22]. Apo E receptors act as signaling molecules in neurons, altering the phosphorylation mechanism of several proteins after extracellular ligand binding and affecting neurite outgrowth, synapse formation and neuronal migration [10].

The results observed in this study regarding the low frequency of the $\varepsilon 4 / \varepsilon 4$ alleles $(1 \%)$ and no association observed in patients with idiopathic PD; agree with the findings observed by Blázquez et al. [23]; in a sample Spanish population of 276 unrelated, familial and sporadic PD patients and in 212 controls, the distribution of Apo $E$ alleles was studied and no significant differences in were found; however, they observed a lower $\varepsilon 4$ allele frequency in the sporadic PD group. In contrast, an increase in $\varepsilon 4$ allele frequency was found in familial PD patients with cognitive decline. The research concludes that the Apo $E \varepsilon 4$ allele may be associated with the risk of developing PD in isolated cases, and that it is linked to the presence of cognitive decline in familial PD. On the other hand, when we analyzed the distribution of the $\varepsilon 3 / \varepsilon 4$ genotype, a significant difference be- 
tween the study groups was observed: OR 3.26(1.63$6.66), p<0.05$. These results are consistent with those reported by Pankratz et al. [24], in a study of 324 Caucasian families, that demonstrated a significantly increased risk of dementia for those individuals who had inherited at least one $\varepsilon 4$ allele $(\mathrm{OR}=3.37 ; \mathrm{P}=0.002)$. There, survival was also analyzed and a significantly earlier age of onset for those subjects with at least one epsilon4 allele was demonstrated (59.7 years). This was also observed in our study when we analyzed the study groups stratified by age and observed that carriers of the $\varepsilon 3 / \varepsilon 4$ alleles at 50 years o more, were at risk: OR 9.7(3.944-24.138) and $p<0.05$.

Other concomitant variables have been associated with PD, like: tobacco, caffeine, exposure to herbicides, solvents and pesticides, and drinking well water [25-28]. In this respect, we observed protective effect of tobacco and caffeine consumption in carriers of the $\varepsilon 3 / \varepsilon 3$, and $\varepsilon 3 / \varepsilon 4$. Stratified analyses such as these have already suggested a genetic environmental interaction between Apo E alleles in the etiology of PD, but the interactions remain controversial. Although the biological basis of the observation that cigarette smoking and caffeine intake protect against PD is controversial, these associations have been studied and found in diverse populations $[25,26]$. In the present study we observed as protect factors the tobacco consumption in patient carriers of $\varepsilon 3 / \varepsilon 3$, and $\varepsilon 3 / \varepsilon 4$ genotypes. Unfortunately, in this study we did not analyze the number and type of cigarettes consumed, the exposure time, or considers the ex-smokers, as well as the amount of caffeine intake. Several hypotheses have been proposed to explain how the nicotine induces detoxifying enzymes, inhibition of bio-activating enzymes and trophic factor stimulation, but none have been proven [25].

Our confirmatory findings support the hypothesis that exposure to pesticides is associated with the risk for PD. The multivariable analysis show that the herbicide, pesticide and solvent exposure had an increased to risk for PD in patients with $\varepsilon 3 / \varepsilon 4$ : OR $5.52(2.52-$ $12.08)$ and $p<0.05$. This result agrees with that reported by Hancock et al. [27], who analyzed the associations of direct pesticide application and observed that insecticides and herbicides were found to significantly increase risk for PD. The specific chemical content of the insecticides has previously been reported to significantly increase PD risk [28]. Studies in animal models have shown that exposure to the herbicide 1,1'-dimethyl-4,4'-bipyridinium, or paraquat (PQ) is a strong risk factor for PD; since, this metabolite crosses the blood-brain barrier, more slowly and to a limited extent than the 1-methyl-4-phenyl-1,2,3,6tetrahydropyridine (MPTP). In mice the PQ causes dose dependent decrease in dopaminergic nigral neurons and striatal dopaminergic innervation, followed by reduced ambulatory movement [29]. The mechanism of action of PQ is believed to be involved in oxidative stress, and due to the similarities of active metabolites of MPTP, 1-methyl-4-phenyl-2,3-dihydropyridinium ion $(\mathrm{MPP}+)$, its toxic effects could be via the mitochondria. PQ, however, is only one of several agricultural chemicals known to adversely impact the dopamine systems. Manganese ethylenebisdithiocarbamate, or maneb, which is used with PQ in overlapping geographical areas, has been shown to decrease locomotor activity and potentiate MPTP effects, suggesting that exposures to mixtures of chemicals may also be etiologically relevant to PD [30]. Probably, the chemicals of pesticides, herbicides and solvents have a synergic effect with the $\varepsilon 4$ allele in PD patients.

In conclusion, our results exhibited that $e 3 / e 4$ genotype of the Apo E polymorphism has significant differences when compared to controls and PD patients. These data suggest that the polymorphism could be a good marker in PD patients; although, it require confirmation in future studies.

\section{References}

[1] A. Lieberman, Depression in Parkinson's disease - a review, Acta Neurol Scand 113 (2006), 1-8.

[2] J.G. Nutt and F. Wooten, Clinical practice. Diagnosis and initial management of Parkinson's disease, N Engl J Med 353 (2005), 1021-1027.

[3] R.L. Nussbaum and C.E. Ellis, Alzheimer's disease and Parkinson's disease, N Engl J Med 348 (2003), 1356-1364.

[4] A.E. Lang and A.M. Lozano, Parkinson's disease. First of two parts, N Eng J Med 339 (1998), 1044-1053.

[5] E. Tolsa, Enfermedad de Parkinson y otros trastornos del movimiento, in: Medicina Interna, F. Rozman, 13 ed., Elsevier press, España, 2001, pp. 1490-1495.

[6] R. Krüger, Parkinson disease, genetic types, Orphanet Encyclopedia (2004), 1-9 (avalaible in http://www.orpha.net/ data/patho/GB/uk-Parkinson.pdf)

[7] G. Utermann, U. Langenbeck, U. Beisiegel and W. Weber, Genetics of the apolipoprotein E system in man, Am J Hum Genet 32 (1980), 339-347.

[8] The French Parkinson's Disease Genetics study group. Apolipoprotein E genotype in familial Parkinson's disease, $J$ Neurol, Neurosurg and Psychiatry 63 (1997), 394-395.

[9] I. Genis, A. Fisher and D.M. Michaelson, Site-specific dephosphorylation of tau of apolipoprotein E-deficient and control mice by M1 muscarinic agonist treatment, J Neurochem 72 (1999), 206-213.

[10] H.S. Hoe, J. Freeman and G.W. Rebeck, Apolipoprotein E decreases tau kinases and phospho-tau levels in primary neurons, Mol Neurodegener 1 (2006), 18. 
[11] L.E. Cruz and J.L. Vázquez, Prevalencia de algunas enfermedades neurológicas en la ciudad de Tepatitlán, Jalisco. México, Rev Mex de Neurol 3 (2002), 71-76.

[12] INEGI. Instituto Nacional de Estadística Geografía e Informática. 2005; Available from: http://www.inegi.gob.mx/ inegi/default.asp. INEGI, 2005.

[13] S.A. Miller, D.D. Dykes and H.F. Polesky, A simple salting out procedure for extracting DNA from human nucleated cell, Nucleic Acids Res 16 (1988), 1215.

[14] J.E. Hixson and D.T. Vernier, Restriction isotyping of human apolipoprotein E by gene amplification and cleavage with $\mathrm{HhI}$, J Lipid Res 31 (1990), 545-548.

[15] C.J. Sanguinetti, E. Dias and A.G. Simpson, Rapid silver staining and recovery of PCR products separated on polyacrylamide gels, Biotechniques 17 (1994), 914-921.

[16] G.M. Souza, N.L. Romano and M.R. Whittle, Efficient mispriming during apolipoprotein E genotyping, J Bras Patol Med Lab 41 (2005), 25-28.

[17] I. Cantuti, C. Keller, B. Bouzou, G. Asteris, T.W. Clark, M.P. Frosch and D.G. Standaert, Effects of gender on nigral gene expression and parkinson disease, Neurobiol Dis 26 (2007), 606-614.

[18] M. Behari, A.K. Srivastava, R.R. Das and R.M. Pandey, Risk factors of Parkinson's disease in Indian patients, J Neurol Sci 1 (2001), 49-55.

[19] F.D. Dick, G. De Palma, A. Ahmadi, N.W. Scott, G.J. Prescott, J. Bennett, S. Semple, S. Dick, C. Counsell, P. Mozzoni, N. Haites, S.B. Wettinger, A. Mutti, M. Otelea, A. Seaton, P. Söderkvist and A. Felice, Geoparkinson study group. Environmental risk factors for Parkinson's disease and parkinsonism: the Geoparkinson study, Occup Environ Med 64 (2007), 666-672.

[20] J.M. Gorell, E.L. Peterson, B.A. Rybicki and C.C. Johnson, Multiple risk factors for Parkinson's disease, J Neurol Sci 217 (2004), 169-174

[21] B. Jasinska, G. Opala, C.G. Goetz, J. Tustanowski, S. Ochudlo, A. Gorzkowska and J. Tyrpa, Apolipoprotein E gene polymor- phism, total plasma cholesterol level, and Parkinson disease dementia, Arch Neurol 64 (2007), 261-265.

[22] G.G. Donohoe, A. Salomäki, T. Lehtimäki, K. Pulkki and V. Kairisto, Rapid identification of apolipoprotein E genotypes by multiplex amplification refractory mutation system PCR and capillary gel electrophoresis, Clin Chem 45 (1999), 143 146.

[23] L. Blázquez, D. Otaegui, A. Sáenz, C. Paisán, J.I. Emparanza, J. Ruiz, F. Moreno, J.F. Martí and A. López, Apolipoprotein E epsilon4 allele in familial and sporadic Parkinson's disease, Neurosci Lett 406 (2006), 235-239.

[24] N. Pankratz, L. Byder, C. Halter, A. Rudolph, C.W. Shults, P.M. Conneally, T. Foroud and W.C. Nichols, Presence of an APOE4 allele results in significantly earlier onset of Parkinson's disease and a higher risk with dementia, Mov Disord 21 (2006), 45-49.

[25] C.M. Tanner, S.M. Goldman, D.A. Aston, R. Ottman, J. Ellenberg, R. Mayeux and J.W. Langston, Smoking and Parkinson's disease in twins, Neurology 58 (2002), 581-588.

[26] G.W. Ross, R.D. Abbott, H. Petrovitch, D.M. Morens, A. Grandinetti, K.H. Tung, C.M. Tanner, K.H. Masaki, P.L. Blanchette, J.D. Curb, J.S. Popper and L.R. White, Association of coffee and caffeine intake with the risk of Parkinson disease, JAMA 283 (2000), 2674-2679.

[27] D.B. Hancock, E.R. Martin, G.M. Mayhew, J.M. Stajich, R. Jewett, M.A. Stacy, B.L. Scott, J.M. Vance and W.K. Scott, Pesticide exposure and risk of Parkinson's disease: a familybased case-control study, BMC Neurol 8 (2008), 6.

[28] F. Kamel and J.A. Hoppin, Association of pesticide exposure with neurologic disfunction and disease, Enviroment Health Perspectives 112 (2004), 950-958.

[29] R. Betarbet and J.T. Greenamyre, Parkinson's disease: animal models, Handb Clin Neurol 83 (2007), 265-287.

[30] G. Klodowska, B. Jasińska, K. Safranow, M. Boczarska and G. Opala, The role of environmental factors in Parkinson's disease may depend on disease onset age, Neurol Neurochir Pol 39 (2005), 445-450. 


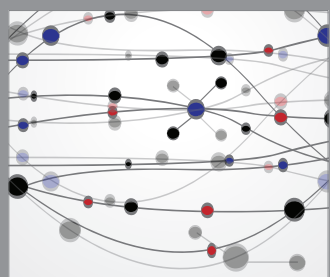

The Scientific World Journal
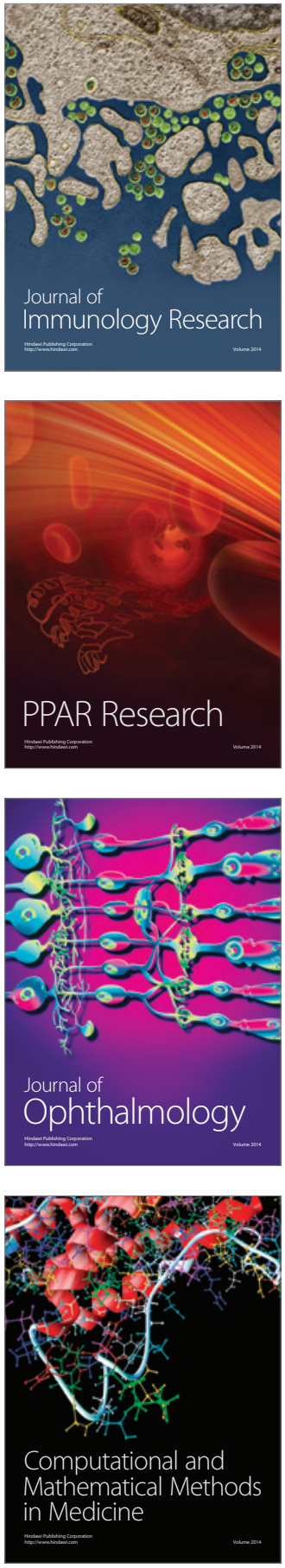

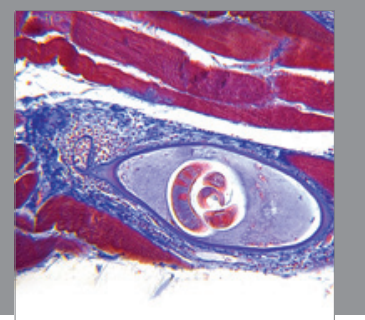

Gastroenterology

Research and Practice
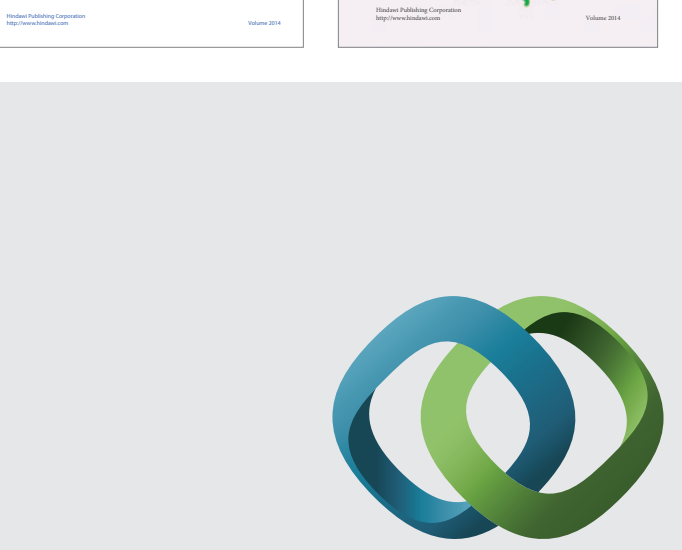

\section{Hindawi}

Submit your manuscripts at

http://www.hindawi.com
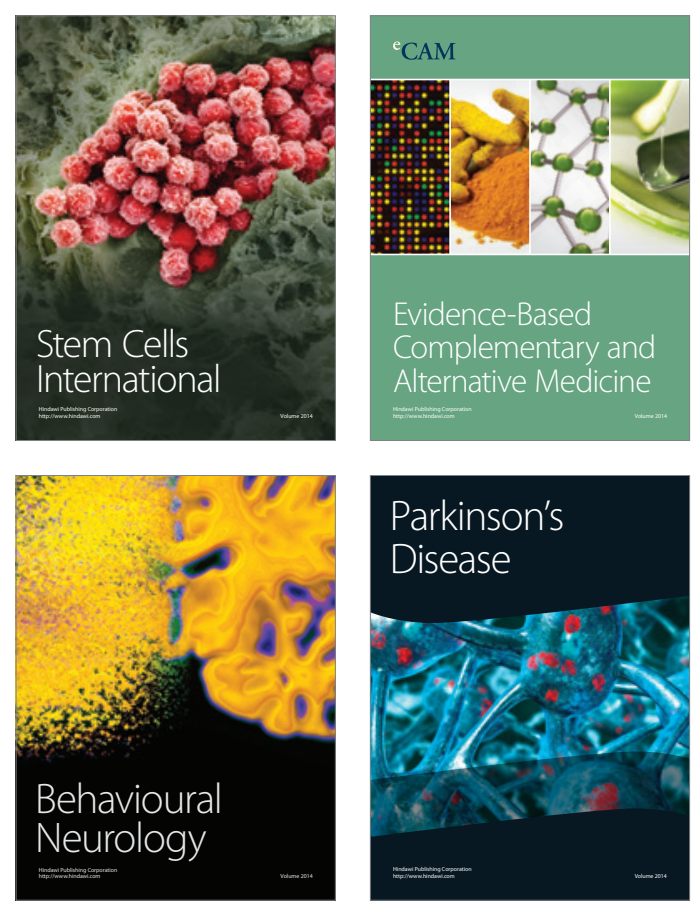

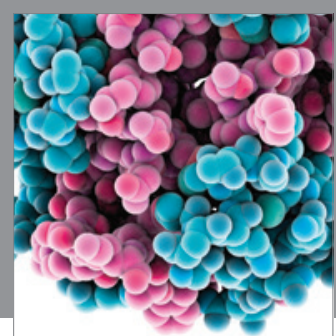

Journal of
Diabetes Research

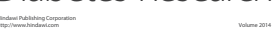

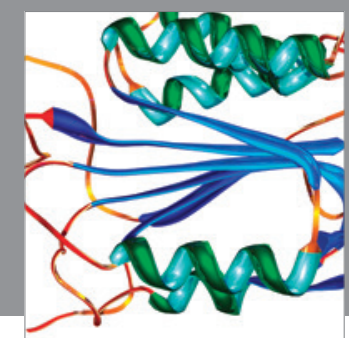

Disease Markers
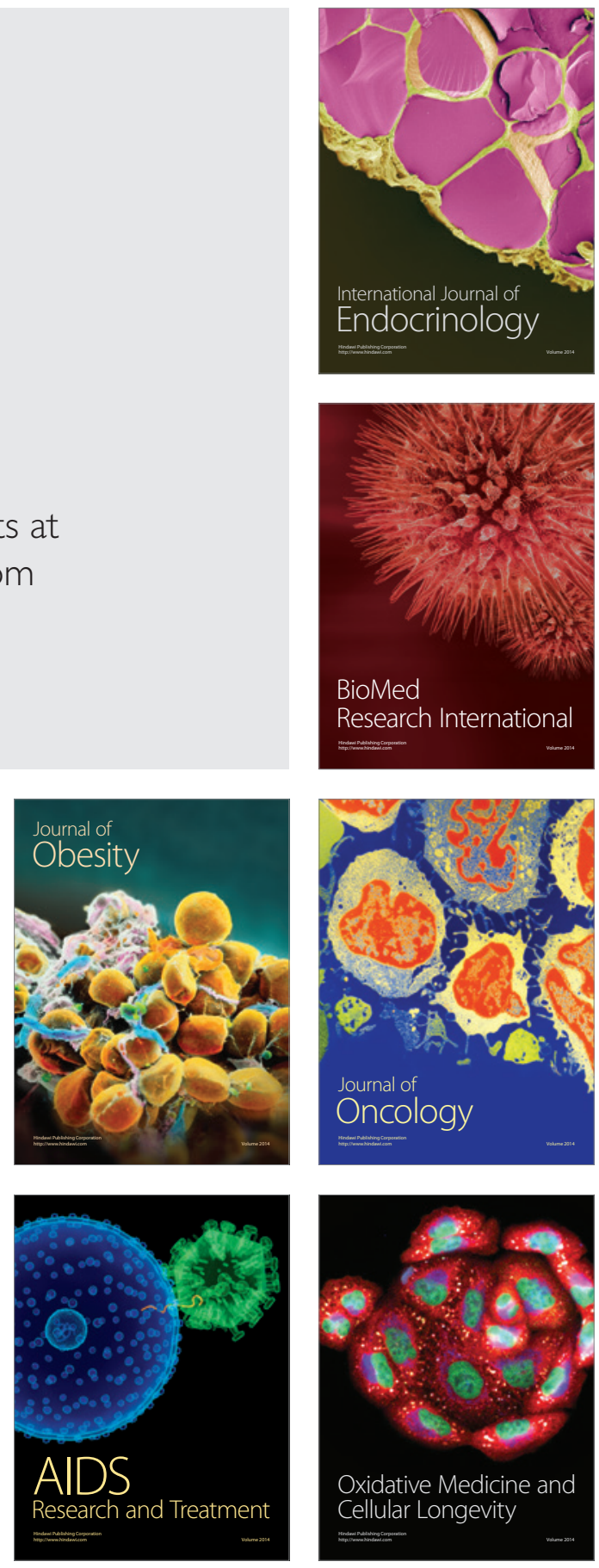